Marquette University

e-Publications@Marquette

Biomedical Engineering Faculty Research and

Publications

Biomedical Engineering, Department of

6-2016

\title{
Image-based Quantification of 3D Morphology for Bifurcations in the Left Coronary Artery: Application to Stent Design
}

\author{
Laura M. Ellwein \\ Virginia Commonwealth University \\ David S. Marks \\ Medical College of Wisconsin \\ Raymond Q. Migrino \\ Medical College of Wisconsin \\ Dennis Foley \\ Medical College of Wisconsin \\ Sara Sherman \\ Virginia Commonwealth University
}

See next page for additional authors

Follow this and additional works at: https://epublications.marquette.edu/bioengin_fac

Part of the Biomedical Engineering and Bioengineering Commons

\section{Recommended Citation}

Ellwein, Laura M.; Marks, David S.; Migrino, Raymond Q.; Foley, Dennis; Sherman, Sara; and LaDisa, John F. Jr., "Image-based Quantification of 3D Morphology for Bifurcations in the Left Coronary Artery: Application to Stent Design" (2016). Biomedical Engineering Faculty Research and Publications. 483. https://epublications.marquette.edu/bioengin_fac/483 


\section{Authors}

Laura M. Ellwein, David S. Marks, Raymond Q. Migrino, Dennis Foley, Sara Sherman, and John F. LaDisa Jr. 
Marquette University

e-Publications@Marquette

\section{Biomedical Engineering Faculty Research and Publications/College of} Engineering

This paper is NOT THE PUBLISHED VERSION; but the author's final, peer-reviewed manuscript. The published version may be accessed by following the link in th citation below.

Catheterization Cardiovascular Interventions, Vol. 87, No. 7 (June 2016): 1244-1255. DOI. This article is (C) Wiley and permission has been granted for this version to appear in e-Publications@Marquette. Wiley does not grant permission for this article to be further copied/distributed or hosted elsewhere without the express permission from Wiley.

\section{Image-Based Quantification Of 3-D Morphology for Bifurcations in The Left Coronary Artery: Application to Stent Design}

\section{Laura Ellwein}

Biomedical Engineering, Marquette University, Milwaukee, WI

David S. Marks

Cardiovascular Medicine, Medical College of Wisconsin, Milwaukee, WI

Raymond Q. Migrino

Cardiovascular Medicine, Medical College of Wisconsin, Milwaukee, WI

VA Health Care System, Phoenix, AZ

W. Dennis Foley

Radiology, Medical College of Wisconsin, Milwaukee, WI

Sara Sherman

Biomedical Engineering, Marquette University, Milwaukee, WI

John F. LaDisa, Jr.

Biomedical Engineering, Marquette University, Milwaukee, WI 
Cardiovascular Medicine, Medical College of Wisconsin, Milwaukee, WI

Biotechnology and Bioengineering Center, Medical College of Wisconsin, Milwaukee, WI

\begin{abstract}
Background

Improved strategies for stent-based treatment of coronary artery disease at bifurcations requires a greater understanding of artery morphology.

Objective

We developed a workflow to quantify morphology in the left main coronary (LMCA), left anterior descending (LAD), and left circumflex (LCX) artery bifurcations.

\section{Methods}

Computational models of each bifurcation were created for 55 patients using computed tomography images in 3D segmentation software. Metrics including cross-sectional area, length, eccentricity, taper, curvature, planarity, branching law parameters, and bifurcation angles were assessed using open-sources software and custom applications. Geometric characterization was performed by comparison of means, correlation and linear discriminant analysis (LDA).

Results

Differences between metrics suggest dedicated or multi-stent approaches should be tailored for each bifurcation. For example, the side branch of the LCX (i.e., obtuse marginal; OM) was longer than that of the LMCA (i.e. LCXprox) and LAD (i.e. first diagonal; D1). Bifurcation metrics for some locations (e.g. LMCA Finet ratio) provide results and confidence intervals agreeing with prior findings, while revised metric values are presented for others (e.g., LAD \& LCX). LDA revealed several metrics that differentiate between artery locations (e.g., LMCA vs D1, LMCA vs OM, LADprox vs D1, and LCXprox vs D1).
\end{abstract}

\title{
Conclusions
}

These results provide a foundation for elucidating common parameters from healthy coronary arteries and could be leveraged in the future for treating diseased arteries. Collectively the current results may ultimately be used for design iterations that improve outcomes following implantation of future dedicated bifurcation stents.

\section{Background}

Improved strategies for stent-based treatment of coronary artery disease at bifurcations requires a greater understanding of artery morphology.

\section{Objective}

We developed a workflow to quantify morphology in the left main coronary (LMCA), left anterior descending (LAD), and left circumflex (LCX) artery bifurcations.

\section{Methods}

Computational models of each bifurcation were created for 55 patients using computed tomography images in 3D segmentation software. Metrics including cross-sectional area, length, eccentricity, taper, curvature, planarity, branching law parameters, and bifurcation angles were assessed using open-sources software and custom applications. Geometric characterization was performed by comparison of means, correlation and linear discriminant analysis (LDA).

\section{Results}

Differences between metrics suggest dedicated or multi-stent approaches should be tailored for each bifurcation. For example, the side branch of the LCX (i.e., obtuse marginal; OM) was longer than that of the 
LMCA (i.e. LCXprox) and LAD (i.e. first diagonal; D1). Bifurcation metrics for some locations (e.g. LMCA Finet ratio) provide results and confidence intervals agreeing with prior findings, while revised metric values are presented for others (e.g., LAD \& LCX). LDA revealed several metrics that differentiate between artery locations (e.g., LMCA vs D1, LMCA vs OM, LADprox vs D1, and LCXprox vs D1).

\section{Conclusions}

These results provide a foundation for elucidating common parameters from healthy coronary arteries and could be leveraged in the future for treating diseased arteries. Collectively the current results may ultimately be used for design iterations that improve outcomes following implantation of future dedicated bifurcation stents.

\section{Introduction}

Coronary bifurcations represent a challenging subset of lesions treated by stents( $\underline{1})$, especially for left main coronary artery (LMCA) lesions that recently underwent a change in classification( $\underline{2}, \underline{3})$. There is a paucity of data on outcomes for specific stents in the LMCA, and some controversy as to whether coronary artery bypass surgery should remain the standard of care for these lesions(4). Current approaches to bifurcation stenting can generally be characterized into multi-stent approaches or dedicated devices. Regardless of approach, selection of a bare metal stent (BMS) or drug-eluting stent (DES) references geometric measurements of length and diameter (i.e. area). A stent or multiple stents within a model platform are then selected based on these metrics, with each stent having been manufactured from a distinct number of circumferential and axial repeating units that satisfies the required diameter and length. While regulatory requirements have certainly been met for these stents, their design attributes may not have been optimized in the strictest sense of the word. For example, we recently showed intrastrut hemodynamics are only optimized over a small range of diameters for one FDA-approved stent studied using idealized models(드). Modifying the stent sizing matrix could extend this finding over a greater range of diameters and engineering metrics of interest(ㅁ).

Prior studies have shown a correlation between artery geometry and atherosclerotic plaque(ㄱ-9 ). Curvature of the coronary arteries impacts local blood flow patterns and plaque distributions $(\underline{10}, \underline{11})$. Similarly, the geometric properties of BMS correlate with neointimal hyperplasia $(\mathrm{NH}$; the primary component of restenosis) $(\underline{12}, \underline{13})$. This correlation is believe to be influenced by mechanical indices such as adverse (i.e. low magnitude and/or oscillatory) wall shear stress (WSS)(14) and pronounced residual wall stress $(\underline{15}, \underline{16})$. More recently reports have shown NH localized to the proximal portion of DES, and suggest that local blood flow patterns may influence the effectiveness of DES agents(17). Depending on its material properties and design features (number of repeating units and connector elements) an implanted stent can also restore or diverge from the normal (and likely preferential) geometry and curvature of a bifurcation region, thereby accentuating adverse mechanical stimuli linked to $\mathrm{NH}$.

With the above in mind, a number of studies have aimed at characterizing geometric features of the coronary artery tree $(\underline{18}-\underline{23})$. Some studies use offline (i.e. outside the cath lab) quantification of CT morphology data to determine the dimensions and approach for stents used to treat bifurcation lesions(24). The objective of the current investigation was to build on this prior research by focusing on the LMCA and its immediate branches where treatment outcomes could be further improved, and to more comprehensively characterize bifurcation morphology using a greater number of metrics and quantification techniques. These results are specifically interpreted relative to the current paradigm of stent design and selection by focusing on unique geometric attributes that may inform future sizing matrices for commercial stents, and suggest different stents/designs for each bifurcation studied here. 


\section{Materials and Methods}

\section{Imaging data collection}

Patients ( $n=67$ ) were imaged as clinically ordered with cardiac gated 64-multislice spiral computed tomography (CT) at Froedert Hospital and the Medical College of Wisconsin (Milwaukee, WI) using conventional parameters and imaging data acquired during cardiac diastasis. All subjects gave written informed consent and Institutional Review Board approval was obtained for the use of patient data. All patient identifiers were excluded during post processing to comply with all Health Insurance Portability and Accountability Act regulations. Operating under the assumption that stenting should restore morphology as close to normal as possible, only arteries that were characterized as normal by the clinician who performed image acquisition were used. Arteries with a diameter stenosis of $>50 \%$, severe plaque burden, poor resolution relative to vessel size, or large septal branches close to the bifurcation were therefore excluded. These criteria provided $n=55$ data sets for modeling construction and geometric analysis.

\section{Model construction}

CT data sets were used to reconstruct geometrically representative computational models of the left coronary artery tree. Artery locations included the LMCA bifurcation, the left anterior descending (LAD), and left circumflex (LCX) arteries, as well as the first diagonal (D1) and the obtuse marginal (OM), the first branches of the LAD and LCX, respectively. 3D segmentation was conducted with the ITK-Snap (www.itksnap.org) opensource software using a semi-automated process. Regions of interest (ROI) determined by image intensity homogeneity were seeded with a series of 3D "snakes" (closed surfaces). The segmentation algorithm allowed snakes to evolve toward the artery wall according to user-defined parameters (i.e. balloon, curvature, advection forces) that acted based on the shape of the snake and the image properties. Segmentation was performed first in the LMCA and the larger portions of the LAD and LCX using image intensity thresholds and balloons for the snake evolution. The initial segmentation was then augmented with paintbrush snakes to seed smaller branches for further segmentation using image edges for preprocessing. Preprocessing and segmentation parameters were chosen to balance consistency between patient data sets and quality data reconstruction( 25 ), and are provided in the appendix. Outputs of the segmentation process included a 3D solid model and a surface mesh of the bifurcation, terminating distally at either the next branch, or when data quality became too poor to segment. Paraview (Kitware; Clifton Park, NY) was used to partition the artery tree into three separate

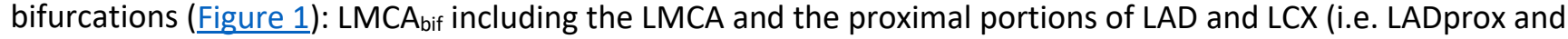
LCXprox, respectively), $L A D_{\text {bif }}$ including the LADprox, distal LAD (i.e. LADdist), and D1, and the $L C X_{\text {bif }}$ including the LCXprox, distal LCX (i.e. LCXdist), and OM. 


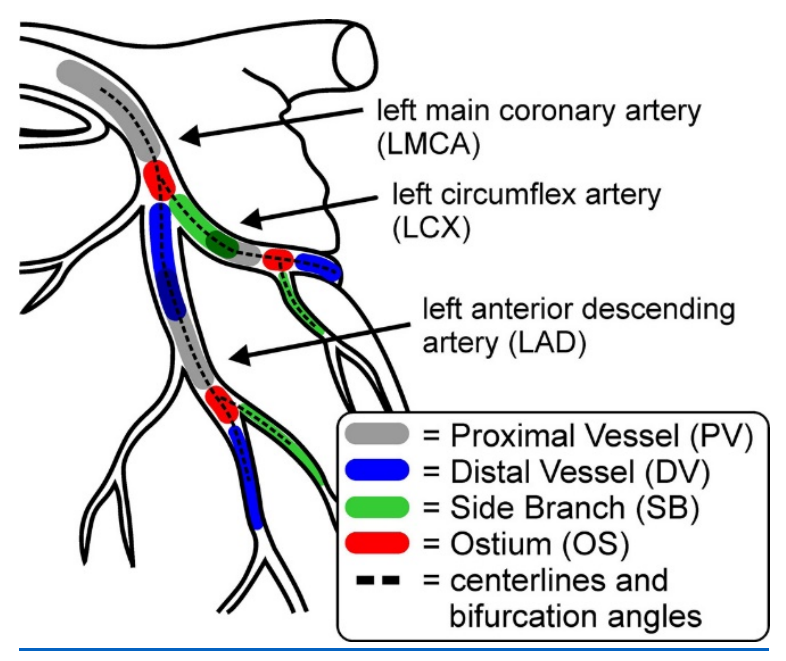

Figure. 1 Diagram of main branches of left coronary bifurcating tree, with definitions of vessel locations.

\section{Geometric analysis}

Surface meshes from the three bifurcations for each patient were imported into VMTK www.vmtk.org) ${ }^{26,27}$ and MATLAB (MathWorks, Natick, MA) to determine centerlines, bifurcation vectors, and metrics (Table 1).

Centerlines were determined in VMTK as the shortest path between the proximal and distal ends of each artery using the centers of maximally inscribed spheres. A reference system for each bifurcation was extracted in VMTK using the centerlines, and the output included bifurcation vectors for each artery determined from a bifurcation plane and associated bifurcation angles (Figure 2). All calculations in VMTK were performed with native scripts. Surface meshes, centerlines, and bifurcation vectors were then queried in MATLAB to divide each bifurcation into artery locations designated as the proximal vessel (PV; the parent portion of the main vessel), the distal vessel (DV; the daughter portion of the main vessel, but also the PV of the daughter branch), the side branch (SB), and the ostium (OS). Thus the D1 and the OM are the SB of the LAD and the LCX, respectively, and the PV of the LAD is considered the DV of the LMCA (Figure 1). The most distal orthogonal plane of the PV is determined as the point where its centerline diverges into DV and SB centerlines. This point also serves as the start point of the OS. The most proximal planes of the DV and SB (i.e., the start of each bifurcation) are determined from their respective centerlines as the first location where the orthogonal planes do not intersect the opposing vessel. The OS end point is calculated as the midpoint of the line connecting the centers of these non-overlapping planes. The OS is comprised of orthogonal planes that extend downstream from the OS start point towards the end point, with no planes overlapping other vessels. 


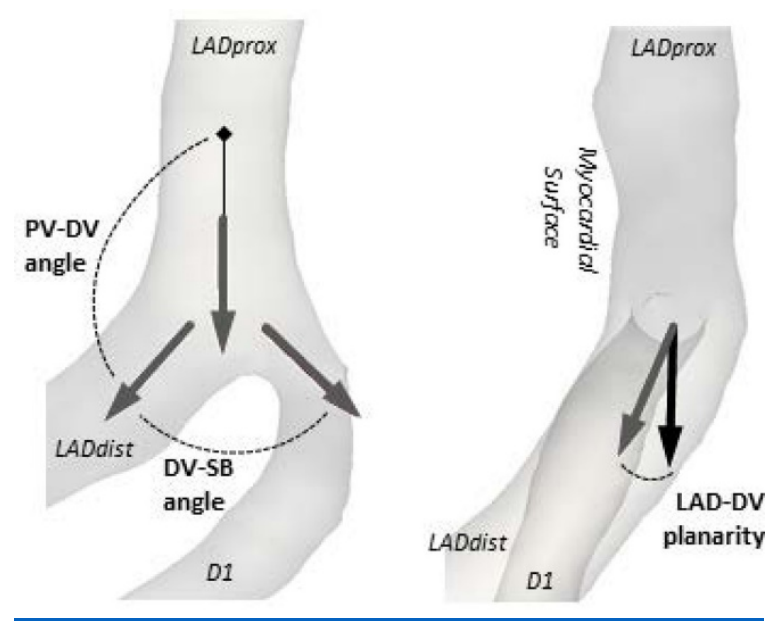

Figure 2 Depiction of bifurcation vectors and planarity of a representative patient LAD bifurcation. Left: Red arrows indicate vectors on the bifurcation plane used to determine PV-DV and DV-SB bifurcation angles. Right: The planarity of each artery at a bifurcation is defined as the angle between its bifurcation vector (gray) and the bifurcation plane (black).

Table 1 Summary of morphological metrics, locations at which they were assessed, the software package used to calculate the metric, and the calculations for the metrics.

\begin{tabular}{|c|c|c|c|c|}
\hline Metric & Locations & Software & Calculation & Transformation \\
\hline Planarity & PV,DV,SB & VMTK & $\angle$ (bifurcation vector - plane) & none \\
\hline Curvature, $C$ & $P V, D V, S B$ & VMTK & $1 / R_{\text {(local osculating circle) }}$ & $C^{-1}$ \\
\hline PV-DV angle & Bifurcation & VMTK & $180-\left(\angle\left(P V_{\text {in-plane }}\right)-\angle\left(D V_{\text {in-plane }}\right)\right)$ & none \\
\hline DV-SB angle & Bifurcation & VMTK & $\angle\left(\mathrm{DV}_{\text {in-plane }}\right)-\angle\left(\mathrm{SB}_{\text {in-plane }}\right)$ & none \\
\hline Length, $L$ & PV,DV,SB,OS & Matlab & $\Sigma$ (centerline segments) & $L^{1 / 2}$ \\
\hline Cross-sectional area, $A$ & PV,DV,SB,OS & Matlab & {$\left[\left(x_{1}+x_{2}\right)\left(y_{1}-y_{2}\right)+\ldots+\left(x_{n}+x_{1}\right)\left(y_{n}-y_{1}\right)\right] / 2$} & $A^{1 / 4}$ \\
\hline Eccentricity, $E$ & $\mathrm{PV}, \mathrm{DV}, \mathrm{SB}, \mathrm{OS}$ & Matlab & $\left(R_{\max }-R_{\min }\right) / R_{\max }$ & $E^{1 / 2}$ \\
\hline Taper, $T$ & PV,DV,SB,OS & Matlab & $\left(D_{\text {prox,mean }}-D_{\text {dist,mean }}\right) /(0.5 \cdot L)$ & none \\
\hline Finet ratio, $F$ & Bifurcation & Matlab & $\mathrm{R}_{\mathrm{PV}} /\left(\mathrm{R}_{\mathrm{DV}}+\mathrm{R}_{\mathrm{SB}}\right)$ & $\log (F)$ \\
\hline k-value & Bifurcation & Matlab & $D_{P V}{ }^{k}=D_{D V}{ }^{k}+D_{S B}{ }^{k}($ solve for $k)$ & $\log (k)$ \\
\hline
\end{tabular}

Each artery location (PV, DV, SB, and OS) was characterized by several metrics (Table 1). Length $L$ of each artery centerline was calculated as the sum of distances between consecutive points defining the centerline. OS length is calculated as the distance between ostial start and end points. Orthogonal segments intersecting the artery lumen surface mesh were determined at $1 \mathrm{~mm}$ increments along each centerline, with the exception of the ostium or arteries $<2 \mathrm{~mm}$ long where segments were extracted every 0.25 or $0.5 \mathrm{~mm}$. Cross-sectional area of segments $A_{s}$ was determined with the MATLAB'polyarea' function, from which mean diameter for each segment, $D_{S}=2 \sqrt{A_{S} / \pi}$, was calculated. Radii $R_{i}$, calculated as the distance from the artery centerline to each point on the segment, were used to calculate eccentricity index, $E_{S}=\frac{R_{\max }-R_{\min }}{R_{\max }}$, and $R_{s}=$ mean $\left(R_{i}\right)$ was computed for each segment(26). $A_{s}, D_{s}$, and $E_{s}$ were then averaged for segments in each artery location to obtain mean $A$, $D$, and $E$. A taper factor for each artery location was calculated as $T=\frac{D_{\text {prox,mean }}-D_{\text {dist,mean }}}{0.5 \cdot L}$. This represents a modification from previous studies $(\underline{27}, \underline{28})$ designed to mitigate the impact of extreme diameters at the inlet and outlet of each branch. Finally, curvature $C$ was calculated at each point along centerlines as the inverse of the radius of the local osculating circle, and reported as an average for each artery location. 
Additional metrics were also quantified for each of the bifurcations $L M C A_{\text {bif, }} L A D_{\text {bif, }}$, and $L C X_{\text {bif }}\left(T_{\text {able }}\right)$. The angles between the DV and the SB (DV-SB) and between the PV and the DV (PV-DV) were calculated as the difference between the projections of their bifurcation vectors onto the bifurcation plane (Figure 2). Planarity of the PV, DV, and SB relative to the bifurcation plane was defined as the angle between the bifurcation vector and the bifurcation plane, with a negative planarity indicating an artery bending towards the heart. Branching at each bifurcation was quantified by two additional metrics based on $R_{s}$ for the segment of each artery closest to each bifurcation. Murray's law for branching(20) states that the radii closest to the bifurcation of a proximal vessel and its distal and side branches are related by $R_{P V}^{k}=R_{D V}^{k}+R_{S B}^{k}$, where $k=3$. An alternative branching law developed by Finet et al $(\underline{18})$ calculated the ratio $F=R_{P V} /\left(R_{D V}+R_{S B}\right.$, found from coronary angiography data to be 0.678 . To compare patient data against these branching laws, the radii, $R_{s}$, were used to calculate $F$ directly and $k$ using a nonlinear solver native to MATLAB.

\section{Statistical Analysis}

The above analyses resulted in 12 measurements per patient of length $L$, mean area $A$, eccentricity $E$, and taper $T$, which are measured at PV, DV, SB, and OS locations of each bifurcation group (i.e. $L M C A_{\text {bif, }} L A D_{\text {bif, }}$, $\left.L C X_{\text {bif }}\right) ; 9$ measurements per patient of planarity and curvature, which are measured at PV, DV, and SB locations of each bifurcation group; and 3 measurements per patient of PV-DV angle, DV-SB angle, Finet ratio, and kvalue, which are measured at each bifurcation plane. Statistical analyses on the 78 measurements were performed with MATLAB and SPSS (Version 21 IBM, Armonk, NY). Parametric statistics were used to allow for a greater selection of statistical analyses and reporting of results consistent with clinical research. Therefore data for each measurement were tested for normality across all groups and locations using both the Lilliefors and Jarque-Bera tests and a visual inspection of histograms. Metrics for which the majority of measurements indicated non-normal distributions underwent a metric-specific transformation to normalize the data (Table 1).

Means of post-transformation data were computed across all patients $(n=55)$. Comparison of means within and between bifurcations was conducted with one-way ANOVA using Tukey-Kramer or Games-Howell post-hoc analyses depending on results from a test for homogeneity of variance. Differences were considered statistically significant for $P<0.05$. Unequal sample sizes were allowed in order to accommodate patient data sets where one or more bifurcations or artery locations were missing viable data. Data was transformed back to original values for reporting purposes, and are expressed as mean and confidence interval. Transformed measurements were also correlated with each other using Pearson's correlation coefficient, first individually resulting in a full $78 \times 78$ correlation matrix, then by bifurcation group and artery location as was used for comparison of means, and finally by comparing metrics across all bifurcation groupings and artery locations based on results from the full correlation matrix. Based on rankings of Pearson's correlation coefficients used elsewhere $(\underline{29}, \underline{30})$, the following system was used to assess the quality of correlation in the current investigation: very strong, $\mathrm{R}>0.9$; strong, $0.7<$ $\mathrm{R}<0.9$; moderate, $0.4<\mathrm{R}<0.7$; low, $\mathrm{R}<0.4$. Coefficients in the strong or very strong categories are highlighted in the Results.

Linear discriminant analysis (LDA) was used to differentiate arteries and bifurcations based on combinations of metrics. The two arteries for which there are two names are each considered as a single artery for the classification analyses, yielding 7 unique arteries for classification (see Figure 1, LMCA DV and LAD PV are both LADprox, and LMCA SB and LCX PV are both LCXprox). LDA was first performed on all 7 arteries with the 5 metrics (i.e. length, area, El, taper, and curvature). Additional specific analyses were done with selected metrics based on those that showed statistical differences from the comparison of means testing. 


\section{Results}

\section{Comparison of means}

\section{Lengths}

For the LMCA and LCX bifurcations, the PV was shorter than the DV and SB, but longer than the OS (e.g. LMCA bif: LMCA $=6.82 \mathrm{~mm}$ vs LADprox $=13.4 \mathrm{~mm}$, LCXprox $=13.8 \mathrm{~mm}$ and OS $_{\mathrm{LMCA}}=3.60 \mathrm{~mm} ;$ LCX $_{\text {bif: }}$ LCXprox $=13.8 \mathrm{~mm}$, $L C X$ dist $=22.4 \mathrm{~mm}$ and $O M=26.0 \mathrm{~mm}$ and $O S_{L C X}=2.70 \mathrm{~mm}$ ). The DV and $S B$ were also longer than the OS in these bifurcations, but otherwise similar. In contrast, for the LAD bifurcation, there were no differences in length between the PV (i.e. LADprox), DV (i.e. LADdist) or SB (i.e. D1), but all were longer than the OS $S_{L A D}$. The PV (i.e. LMCA) and DV (i.e. LADprox) of the LMCA bifurcation were shorter than the respective PV and DV of the LAD and LCX. In contrast, the OS $S_{L M C A}$ was longer than that of the LAD and LCX (e.g. OS $S_{L M C A}=3.60 \mathrm{~mm}$ vs $O S_{L A D}=2.92$ $\mathrm{mm}$ and $\mathrm{OS}_{\mathrm{LCX}}=2.70 \mathrm{~mm}$ ). The SB of the LCX (i.e. OM) was longer than that of the LMCA (i.e. LCXprox) and LAD (i.e. D1).

\section{Areas}

The area of the PV for the LMCA, LAD and LCX bifurcations was significantly larger than that of the respective DV and SB, but not the OS. Additionally, the area of the DV of the LAD bifurcation (i.e. LADdist) was also significantly larger than that of the SB (i.e. OM). Not surprisingly, all artery locations within the LMCA have a significantly larger area than their corresponding locations of the LAD and LCX bifurcations. Additionally, the area of the DV of the LAD is larger than that of the LCX, but the area of the SB of the LAD is smaller than for the LCX.

\section{Eccentricity}

The OS was the most eccentric and significantly different from all other artery locations within a given bifurcation. Within the LAD bifurcation, the SB (i.e. D1) was more eccentric than the PV (i.e. LADprox) and DV (i.e. LADdist) (e.g. LADprox $=0.199$, LADdist $=0.197$ and D1 $=0.234$ ). The SB (i.e. OM) of the LCX bifurcation also had a higher eccentricity index than the PV (i.e. LCXprox). This eccentricity of the SB of the LAD and LCX bifurcations was significantly more pronounced than the SB of the LMCA (i.e. the LCXprox).

\section{Taper}

Similar to the observations of eccentricity, the OS tapered significantly more than the other three locations of all three bifurcations.

\section{Planarity}

Planarity for the three artery locations (PV, DV and SB) of the LMCA and LAD bifurcations were all directed towards the heart and of similar magnitude $\left(L_{M C A_{\text {bif: }}: P V=-5.50, D V=-5.14, S B=-4.36 ;} L A D_{\text {bif: }} P V=-1.16\right.$, $D V=-2.09, S B=-2.34)$. However, for the $L C X$ bifurcation, the PV vector (i.e. LCXprox) was pointed away from the heart (1.45) and was in the opposite direction of the SB (i.e. OM; -2.732). Planarity of the PV for the LMCA $A_{\text {bif }}$ was directed significantly more towards the heart than that of the $L A D_{\text {bif }}$ and $L C X_{\text {bif. }}$ Planarity of the $L M C A_{\text {bif }} D V$ was also directed significantly more towards the heart than the $L C X_{\text {bif }}$, but the planarity of all SB pointed towards the heart with similar magnitude $\left(\operatorname{LMCA}_{\text {bif }}=-4.36, \mathrm{LAD}_{\text {bif }}=-2.34, \mathrm{LCX}_{\mathrm{bif}}=-2.73\right)$.

\section{Curvature}

Within the LMCA bifurcation, curvature was significantly less pronounced along the DV (i.e. LADprox), relative to the PV (i.e. LMCA) and SB (i.e. LCXprox). In contrast, within the LAD and LCX bifurcations, the curvature of PV (i.e. LADprox and LCXprox, respectively) were significantly more pronounced than their respective downstream DV locations, and their respective SB (i.e. D1 and OM, respectively) had significantly greater curvature than the other two artery locations within these bifurcations. Curvature along the PV of the LAD bifurcation was significantly less than the LMCA and LCX bifurcations. The DV artery location between bifurcations revealed 
significantly more curvature for the LCX bifurcation as compared to the LMCA and LAD bifurcations. Similarly, the SB artery location between bifurcations contained greater curvature for the LAD bifurcation (i.e. D1) and LCX bifurcation (i.e. OM) as compared to LMCA bifurcation (i.e. LCXprox). The curvature of the D1 SB was statistically more pronounced than the OM.

\section{Bifurcation metrics}

The PV-DV angle of the LAD bifurcation was significantly higher than for the LMCA bifurcation and LCX bifurcation $\left(\mathrm{LAD}_{\text {bif }}=161.1^{\circ}\right.$ vs $L M C A_{\text {bif }}=147.6^{\circ}$ and $\left.L C X_{\text {bif }}=148.0^{\circ}\right)$, conversely, the DV-SB angle was not different between bifurcations. In the LMCA bifurcation, the Finet ratio was significantly lower and the k-value significantly higher than in the LAD bifurcation or LCX bifurcation (Table 2 ).

Table 2 Artery geometric and bifurcation metrics. 95\% confidence intervals, [Cl].

\begin{tabular}{|c|c|c|c|c|c|c|c|c|}
\hline & Length (mm) & & & & & & & \\
\hline & PV & & DV & & SB & & OS & \\
\hline LMCA & $6.82[5.52,8.25]$ & $\dagger$ & $\begin{array}{l}13.35[10.55 \\
16.49]\end{array}$ & ${ }^{*+}$ & $13.79[10.6,17.38]$ & ${ }^{*+}$ & $3.60[3.33,3.88]$ & $*$ \\
\hline LAD & $\begin{array}{l}13.35 \text { [10.55, } \\
16.49]\end{array}$ & $\dagger \neq$ & $\begin{array}{l}19.99 \text { [15.94, } \\
24.50]\end{array}$ & $\dagger \ddagger$ & $\begin{array}{l}16.31[13.26 \\
19.66]\end{array}$ & $\dagger$ & $2.92[2.64,3.21]$ & ${ }^{*} \neq$ \\
\hline \multirow[t]{3}{*}{ LCX } & $13.79[10.6,17.38]$ & $† \ddagger$ & $\begin{array}{l}22.56[18.40 \\
27.14]\end{array}$ & $*+\neq$ & $\begin{array}{l}25.81[21.44, \\
30.69]\end{array}$ & ${ }^{*}+\neq \neq$ & $2.70[2.38,3.04]$ & ${ }^{*} \ddagger$ \\
\hline & Area $\left(\mathrm{mm}^{2}\right)$ & & & & & & & \\
\hline & PV & & DV & & SB & & OS & \\
\hline LMCA & $\begin{array}{l}15.43 \text { [13.81, } \\
17.21]\end{array}$ & & $9.64[8.57,10.83]$ & * & $8.81[7.74,9.99]$ & * & $\begin{array}{l}17.76 \text { [16.1, } \\
19.58]\end{array}$ & \\
\hline LAD & $9.64[8.57,10.83]$ & $\ddagger$ & $7.18[6.15,8.34]$ & $* \S \ddagger$ & $1.92[1.68,2.19]$ & $* \ddagger$ & $\begin{array}{l}10.06 \text { [8.81, } \\
11.45]\end{array}$ & $\neq$ \\
\hline \multirow[t]{3}{*}{ LCX } & $8.81[7.74,9.99]$ & $\ddagger$ & $4.32[3.44,5.37]$ & *¥¥ & $3.09[2.56,3.70]$ & ${ }^{*} \neq ¥$ & $9.70[8.57,10.93]$ & $\ddagger$ \\
\hline & Eccentricity & & & & & & & \\
\hline & PV & & DV & & SB & & OS & \\
\hline LMCA & $\begin{array}{l}0.210[0.192, \\
0.229]\end{array}$ & + & $\begin{array}{l}0.199[0.184, \\
0.215]\end{array}$ & + & $\begin{array}{l}0.185[0.170, \\
0.201]\end{array}$ & + & $\begin{array}{l}0.308[0.283, \\
0.333]\end{array}$ & \\
\hline LAD & $\begin{array}{l}0.199[0.184, \\
0.215]\end{array}$ & $+\S$ & $\begin{array}{l}0.197[0.183 \\
0.212]\end{array}$ & †ई & $\begin{array}{l}0.234[0.221 \\
0.248]\end{array}$ & $*+\neq$ & $\begin{array}{l}0.308 \text { [0.283, } \\
0.334]\end{array}$ & \\
\hline \multirow[t]{3}{*}{ LCX } & $\begin{array}{l}0.185 \text { [0.170, } \\
0.201]\end{array}$ & $+\S$ & $\begin{array}{l}0.203 \text { [0.188, } \\
0.219]\end{array}$ & + & $\begin{array}{l}0.225[0.208 \\
0.243]\end{array}$ & $*+\neq$ & $\begin{array}{l}0.311[0.285 \\
0.340]\end{array}$ & \\
\hline & Taper & & & & & & & \\
\hline & PV & & DV & & SB & & OS & \\
\hline LMCA & $\begin{array}{l}0.001[-.059 \\
0.062]\end{array}$ & $\dagger$ & $\begin{array}{l}0.008[-0.007 \\
0.024]\end{array}$ & $\dagger$ & $\begin{array}{l}0.028[-0.002 \\
0.058]\end{array}$ & + & $\begin{array}{l}-0.183[0.134 \\
0.231]\end{array}$ & \\
\hline LAD & $\begin{array}{l}0.008[-0.007, \\
0.024]\end{array}$ & ${ }^{\dagger}$ & $\begin{array}{l}0.014[0.003 \\
0.025]\end{array}$ & ${ }^{\dagger}$ & $\begin{array}{l}0.036[0.017 \\
0.054]\end{array}$ & ${ }^{\dagger}$ & $\begin{array}{l}-0.143 \text { [0.101, } \\
0.185]\end{array}$ & \\
\hline \multirow[t]{3}{*}{ LCX } & $\begin{array}{l}0.028[-0.002, \\
0.058]\end{array}$ & ${ }^{\dagger}$ & $\begin{array}{l}0.015[0.002, \\
0.028]\end{array}$ & ${ }^{\dagger}$ & $\begin{array}{l}0.020[0.007 \\
0.032]\end{array}$ & ${ }^{\dagger}$ & $\begin{array}{l}-0.122[0.088 \\
0.155]\end{array}$ & \\
\hline & Planarity (deg) & & & & & & & \\
\hline & PV & & DV & & SB & & & \\
\hline LMCA & $\begin{array}{l}-5.50[-7.52 \\
-3.48]\end{array}$ & & $\begin{array}{l}-5.14[-7.52 \\
-2.77]\end{array}$ & & $\begin{array}{l}-4.36[-6.92 \\
-1.80]\end{array}$ & & & \\
\hline LAD & $-1.16[-3.07,0.75]$ & $\ddagger$ & $\begin{array}{l}-2.09[-3.63 \\
-0.56]\end{array}$ & & $-2.34[-4.83,0.16]$ & & & \\
\hline
\end{tabular}




\begin{tabular}{|c|c|c|c|c|c|c|c|}
\hline LCX & $1.45[-0.93,3.82]$ & $\neq \S$ & $-0.09[-2.37,2.19]$ & $\neq \S$ & $\begin{array}{l}-2.73[-5.02, \\
-0.44]\end{array}$ & & \\
\hline & Curvature $\left(\mathrm{mm}^{-1}\right)$ & & & & & & \\
\hline & PV & & DV & & SB & & \\
\hline LMCA & $\begin{array}{l}0.111 \text { [0.101, } \\
0.122]\end{array}$ & & $\begin{array}{l}0.089[0.083, \\
0.096]\end{array}$ & *§ & $\begin{array}{l}0.103 \text { [0.093, } \\
0.144]\end{array}$ & & \\
\hline LAD & $\begin{array}{l}0.089[0.083, \\
0.096]\end{array}$ & $\ddagger$ & $\begin{array}{l}0.107[0.098 \\
0.118]\end{array}$ & *§‡ & $\begin{array}{l}0.228[0.207, \\
0.255]\end{array}$ & $* \ddagger$ & \\
\hline \multirow[t]{3}{*}{ LCX } & $\begin{array}{l}0.103 \text { [0.093, } \\
0.144]\end{array}$ & * & $\begin{array}{l}0.127[0.112, \\
0.146]\end{array}$ & ${ }^{*} \ddagger$ & $\begin{array}{l}0.170[0.152, \\
0.192]\end{array}$ & *¥¥ & \\
\hline & Bifurcation metrics & & & & & & \\
\hline & PV-DV angle (deg) & & & & Finet ratio & & k-value \\
\hline LMCA & $\begin{array}{l}147.6[144.3, \\
151.0]\end{array}$ & & & & $\begin{array}{l}0.668 \text { [0.635, } \\
0.705]\end{array}$ & & $2.67[2.25,3.16]$ \\
\hline LAD & $\begin{array}{l}161.1 \text { [158.3, } \\
163.9]\end{array}$ & $\neq$ & $68.7[64.1,72.6]$ & & $\begin{array}{l}0.865[0.820 \\
0.914]\end{array}$ & $\neq$ & $1.28[1.15,1.43]$ \\
\hline LCX & $\begin{array}{l}148.0[142.7, \\
153.3]\end{array}$ & $¥$ & $71.4[66.4,76.3]$ & & $\begin{array}{l}0.962[0.885, \\
1.046]\end{array}$ & $\neq$ & $1.14[1.00,1.31]$ \\
\hline
\end{tabular}

${ }^{*}=$ significantly $(\mathrm{P}<0.05)$ different from the $\mathrm{PV}$ artery location,

${ }^{+}=$significantly $(P<0.05)$ different from the OS artery location,

$\S=$ significantly $(P<0.05)$ different from the SB artery location,

${ }^{\ddagger}=$ significantly $(P<0.05)$ different from the LMCA bifurcation,

${ }^{*}=$ significantly $(P<0.05)$ different from the LAD bifurcation

\section{Correlations}

The full coefficient matrix indicates a high incidence of strong and very strong positive correlations among crosssectional area (Table 3 ). In particular, very strong correlations occur in the LMCA and LCX bifurcations between the PV and the OS ( $R=0.918$ \& 0.932 , respectively). The next highest strong correlation occurred in the LAD bifurcation between the PV and the OS $(R=0.869)$. Additionally we note that within the LMCA bifurcation all area correlations are strong or very strong with the exception of the moderate correlation between the DV and SB (i.e. LADprox and LCXprox, respectively). In lieu of presenting the full $78 \times 78$ matrix in annotated form, we highlight the remaining strong and very strong correlations between individual measurements among all metrics: $L A D_{\text {bif }} O S$ area vs. length $(R=0.704) ; L A D_{\text {bif }} D V-S B$ angle vs. length $(R=-0.714) ; L A D_{\text {bif }} S B$ area (D1) vs. curvature ( $R=0.761)$; $L C X_{\text {bif }} D V(L C X p r o x)$ area vs. curvature $(R=0.736) ; L M C A_{\text {bif }} k$-value vs. Finet ratio $(R=-0.920)$; $L A D_{\text {bif }} k-v a l u e v s$. Finet ratio $(R=-0.954)$; and $L C X_{\text {bif }} k$-value vs. Finet ratio $(R=-0.954)$.

Table 3 Correlation coefficients and p-values for all cross-sectional areas between individual metrics, arranged by bifurcation and artery location. Note that the LMCA DV is the same artery location as the LAD PV, likewise the LMCA SB is the same artery as LCX PV. Dark grey with bold text, $R>0.9$; medium grey, $0.7<R<0.9$; light grey, $0.4<$ $R<0.7$; white, $R<0.4$. The strongest correlations occur within the LMCA bifurcation.

\begin{tabular}{|c|c|c|c|c|c|c|c|c|c|c|c|c|c|c|}
\hline & & & $\begin{array}{l}\text { LMC } \\
\text { A }\end{array}$ & & & & LAD & & & & LCX & & & \\
\hline & & & PV & DV & SB & OS & PV & DV & SB & OS & PV & DV & SB & OS \\
\hline $\begin{array}{l}\text { LMC } \\
A\end{array}$ & $\begin{array}{l}P \\
V\end{array}$ & $\begin{array}{l}\text { Cor } \\
\text { r. }\end{array}$ & & $\begin{array}{l}0.73 \\
6\end{array}$ & $\begin{array}{l}0.71 \\
5\end{array}$ & $\begin{array}{l}0.91 \\
8\end{array}$ & $\begin{array}{l}0.73 \\
6\end{array}$ & $\begin{array}{l}0.56 \\
9\end{array}$ & $\begin{array}{l}0.48 \\
8\end{array}$ & $\begin{array}{l}0.53 \\
4\end{array}$ & $\begin{array}{l}0.71 \\
5\end{array}$ & $\begin{array}{l}0.64 \\
2\end{array}$ & $\begin{array}{l}0.28 \\
0\end{array}$ & $\begin{array}{l}0.75 \\
9\end{array}$ \\
\hline & & Sig. & & $\begin{array}{l}<0.0 \\
01\end{array}$ & $\begin{array}{l}<0.0 \\
01\end{array}$ & $\begin{array}{l}<0.0 \\
01\end{array}$ & $\begin{array}{l}<0.0 \\
01\end{array}$ & $\begin{array}{l}<0.0 \\
01\end{array}$ & $\begin{array}{l}0.00 \\
1\end{array}$ & $\begin{array}{l}<0.0 \\
01\end{array}$ & $\begin{array}{l}<0.0 \\
01\end{array}$ & $\begin{array}{l}<0.0 \\
01\end{array}$ & $\begin{array}{l}0.05 \\
6\end{array}$ & $\begin{array}{l}<0.00 \\
1\end{array}$ \\
\hline
\end{tabular}




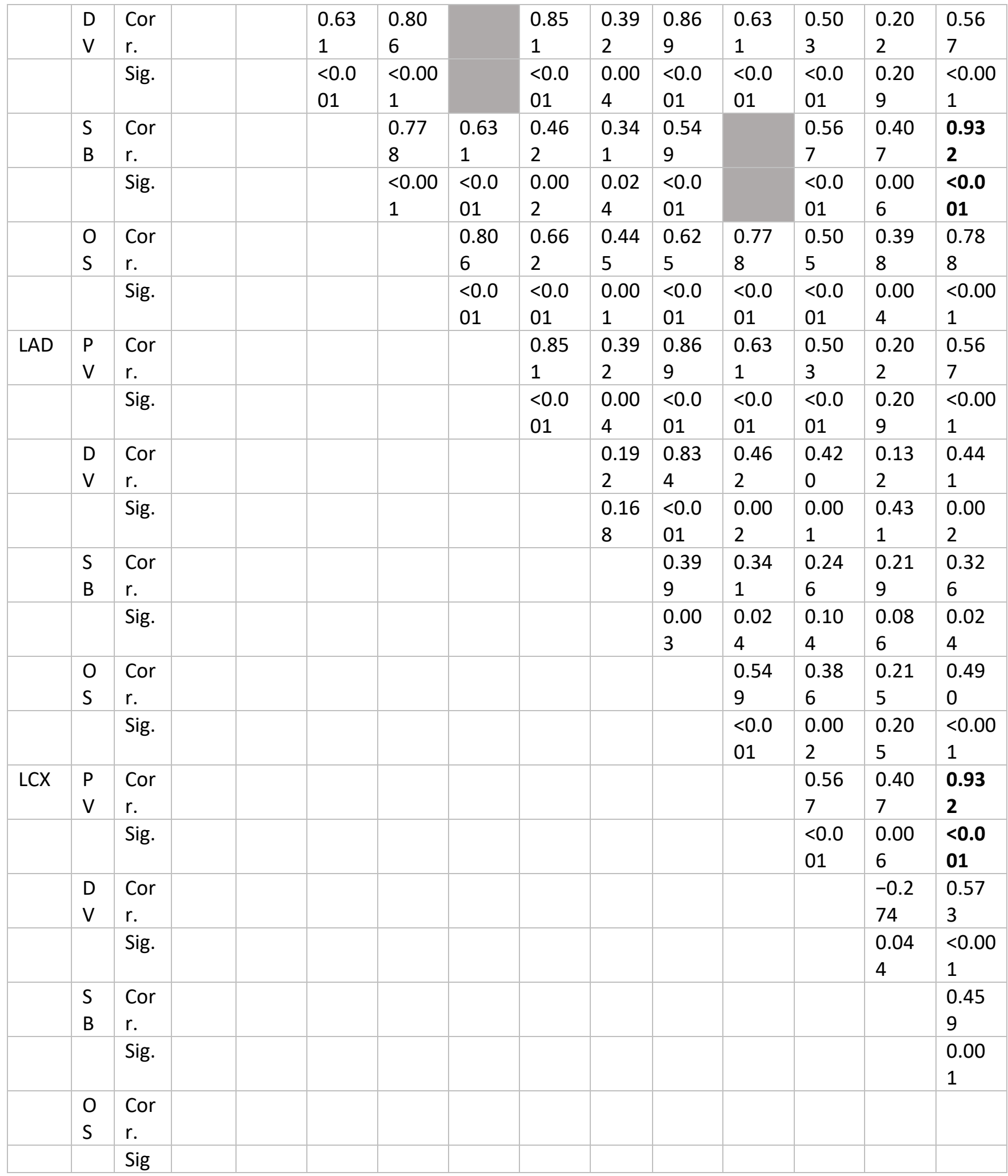

Transformed measurements were also correlated using the same bifurcation groups and artery locations as for the comparison of means. In particular, there was a very strong correlation between PV and OS areas across all bifurcations ( $R=0.926$, Figure 3 ). Strong correlations also exist between the $P V$ and $D V(R=0.731)$ and $D V$ and OS $(R=0.743)$ areas. Between bifurcation groups, the $L M C A_{\text {bif }}$ area is strongly correlated with the $L A D_{\text {bif }}$ and $L C X_{\text {bif areas }}(\mathrm{R}=.703$ and $\mathrm{R}=0.722$ respectively). All other correlations for these groupings were moderate to low. 


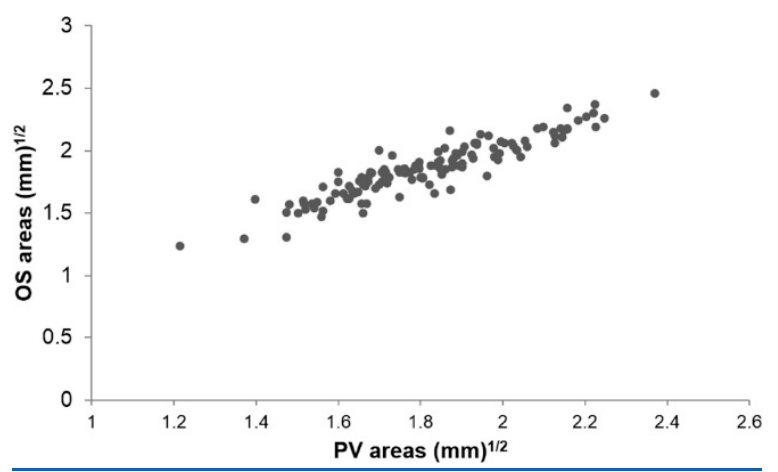

Figure 3 Transformed correlation results for cross-sectional areas of parent vessels (PV) vs. ostia (OS), across all three bifurcations. $\mathrm{R}=0.926$.

A strong correlation between area and curvature was also noted across all artery locations in the $L A D_{\text {bif }}(R=0.821)$. In addition, a very strong negative correlation $(R=-0.945)$ between transformed Finet ratio and k-value was found across all data (Figure 4, left). However, the data indicates a possible nonlinear relationship between $\log (k)$ and $\log (F)$, so using Pearson's coefficient is likely not the most accurate measure of dependence between the two variables. To estimate the true relationship between $k$ and $F$ we solved $R_{P V}^{k}=R_{D V}^{k}+$

$R_{S B}^{k}$ for $k$ with the assumption that $R_{D V}$ and $R_{S B}$ are close enough in value such that $R_{D V} / R_{S B} \approx 1$. Combining this result with the Finet ratio we determined that $k=\left(\log _{2} 2 F\right)^{-1}$. When new $k$ values were calculated with $F$ from the data, a curve that passes through a majority of the data points is obtained (Figure 4, right), thus substantiating the claims that $R_{D V} \approx R_{S B}$ and the relationship between the metrics is highly nonlinear.

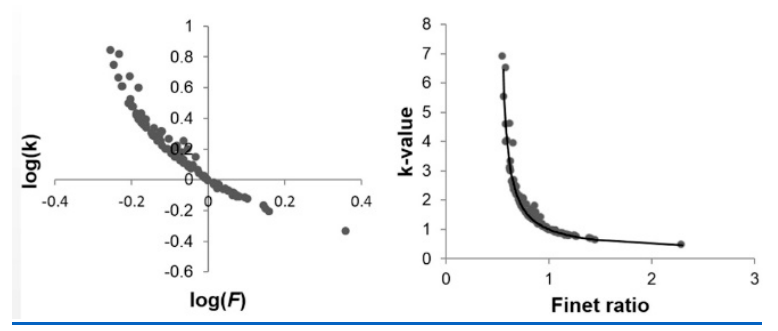

Figure 4 Left: Log-transformed k-value vs. Finet ratio for the set of patients showing high negative correlation with Pearson's coefficient $R=-0.945$. There is evidence of a nonlinear relationship between the two metrics. Right: Original k-value vs. Finet ratio data plot with a plot of $k_{\text {calculated }}=\left(\log _{2} 2 F_{\text {data }}\right)^{-1}$, indicating the derived equation represents the nonlinear relationship between the two metrics.

\section{Linear discriminant analysis}

LDA revealed that the 7 seven arteries as a group could not be differentiated by the set of 5 metrics, nor by removing taper and then El from the set, with resubstitution errors of $50.1 \%, 49.9 \%$, and $53.6 \%$ respectively. When arteries were analyzed pairwise however, length, area, and curvature could differentiate between LMCA vs D1, LMCA vs OM, LADprox vs D1, and LCXprox vs D1, with resubstitution errors less than $5 \%$ (Table $\underline{4}$ and Figure 5 , left). Resubstitution error is as high as $13 \%$ for the cases LMCA vs LCXdist, LADprox vs OM, and LCXprox vs OM, but remaining artery pairings could not be distinguished from one another. LDA was also performed on the group of three bifurcations with the two metrics PV-DV angle and k-value. Resubstitution error was $30.3 \%$ when comparing LMCA, LAD, and LCX bifurcations separately, but $11.0 \%$ when considering the $L A D$ and $L C X$ together as one group (Figure 5 , right). 


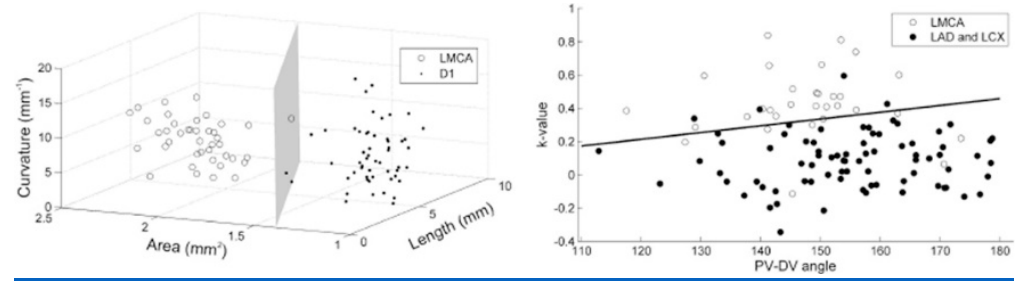

Figure 5 (Left) Plot of LMCA and D1 length, area, and curvature. The linear classification boundary is given by the green plane. The resubstitution error in this case was 1.1\%, caused by the one LMCA data point (circles) on the D1 side of the boundary. (Right) Plot of k-value vs PV-DV angle for the LMCA and the two next-level bifurcations, resubstitution error $11.0 \%$.

Table 4 Resubstitution error from linear discriminant analysis using length, area, and curvature as metrics to differentiate the arteries. The artery pairs LMCA vs D1, LMCA vs OM, LADprox vs D1, and LCXprox vs D1 could be classified with these three metrics with error $<5 \%$.

\begin{tabular}{|l|l|l|l|}
\hline & LCXdist & D1 & OM \\
\hline LMCA & $5.4 \%$ & $1.1 \%$ & $3.2 \%$ \\
\hline LADprox & $5.8 \%$ & $4.7 \%$ & $8.8 \%$ \\
\hline LCXprox & $10.4 \%$ & $4.1 \%$ & $13.4 \%$ \\
\hline
\end{tabular}

\section{Discussion}

Restenosis rates among DES remains $~ 10 \%$ with the current approach to stent selection, which impacts $\sim 200,000$ patients per year in the U.S. alone(31) and is more pronounced for bifurcation lesions( $\underline{1})$. Here we build on prior research that has characterized coronary artery bifurcation morphology by focusing on the LMCA and its immediate branches (LAD/D1 and LCX/OM) where treatment outcomes after stenting could be further improved to reduce restenosis rates. The results provide one of the most comprehensive pictures of LMCA bifurcation morphology to date by including metrics that are commonly reported of length, area, bifurcation angle, Finet ratio, k-value, as well as less common metrics of eccentricity, taper, planarity, and curvature. Beyond this geometric characterization, correlation and LDA were performed to determine if arteries and bifurcations could be differentiated by a subset of metrics. The discussion below focuses on interpretation of results relative to the current paradigm of stent design and selection using geometric attributes. This work may ultimately inform future sizing matrices for commercial stents, and suggest different stents or designs for each bifurcation group or artery locations characterized here. There are several key findings from the present investigation.

1. Values and confidence intervals are provided for geometry metrics corresponding to bifurcations within three prominent branches of the LMCA. These values obtained from 55 patients elucidate normal ranges that may assist in the design of next-generation dedicated bifurcation stents.

2. Differences between the LMCA, LAD and LCX bifurcations, particularly for SB metrics of length and area, raise the intriguing question of whether dedicated bifurcation designs or multi-stent approaches should be further tailored for each bifurcation.

3. Strong correlations between PV and OS area regardless of bifurcation group may provide an additional clinical measurement to assist with restoring challenging ostium lesions to potentially more natural dimensions using dedicated or multi-stent approaches. 
4. The bifurcation metrics quantified (e.g. DV-SB bifurcation angle, Finet ratio) provide values and confidence intervals that only partially align with values in the literature.

5. LDA revealed several metrics that differentiate between artery locations and bifurcations. These results could be used in a more population-based approach to stent design, or to select an existing stent that optimizes a greater number of geometric and bifurcation metrics.

Current dedicated bifurcation stents employ a range of dimensions in their geometric parameters. The Tryton Side Branch Stent (Tryton Medical, Durham, NC) provides scaffolding for the SB, radial strength in the OS region, and a few struts in the PV region. PV diameters from 2.5-4.5 $\mathrm{mm}$ are accommodated, and SB deployment diameters can be $0.5-1.0 \mathrm{~mm}$ less than the deployed PV diameter(32). The Tryton stent comes in standard (18$19 \mathrm{~mm}$ ) and short (15 mm) lengths, each with a $4.5 \mathrm{~mm}$ transition to be deployed near the OS. These target deployment and transition dimensions are in agreement with the PV and SB diameters, and OS lengths reported here. In contrast to the Tryton Side Branch Stent, the Axxess nitinol bifurcation stent (Biosensors International; Lausanne, Switzerland) focuses on the PV and OS, and is designed for the PV and OS with reference vessel diameters from 2.75 to $3.75 \mathrm{~mm}(\underline{33})$. The Axxess stent is available in 11 or $14 \mathrm{~mm}$ lengths, which seems appropriate assuming plaque only spans a portion of the collective PV and OS lengths presented here. However, the current results suggest the Axxess stent is undersized relative to the normal diameters of the PV and OS. The Stentys stent design (Stentys Inc., Princeton, NJ) is a self-expandable Nitinol stent used for provisional stenting that is delivered as a single stent. After expansion of the stent within PV and DV the catheter can be retracted and repositioned in the SB where the balloon can be expanded to dislodge (i.e. fracture) a break-away section of stent. This action deforms the local portion of the stent towards the SB wall in order to provide increased SB patency. The Stentys design is available in small $(2.5-2.0 \mathrm{~mm})$, medium $(3.0-3.5 \mathrm{~mm})$ and large $(3.5-4.5 \mathrm{~mm})$ diameters and 17, 22 or $27 \mathrm{~mm}$ lengths, which are aligned with the dimensions reported here. Unfortunately, prior studies and feelings among key opinion leaders suggest current single and multistent approaches result in better outcomes than dedicated bifurcations devices developed to date(34-36). The current results may therefore be used for design iterations that ultimately improve outcomes, and hence further temper skepticism, following implantation of future dedicated bifurcation stents.

The current results also indicate a given artery becomes more curved as it progresses distally along the epicardial surface. The majority of commercial stent designs available do not accommodate taper in that the amount of material and distance between struts is often uniform throughout the length and circumference of the stent. We have previously optimized intrastrut WSS as a function of vessel diameter by altering the number of repeating circumferential units for a stent $(\underline{5})$. The significant results for curvature, planarity and the geometric metrics from the current investigation mentioned above may be used to further optimize the design of future dedicate stents in a manner that also reduces the likelihood for restenosis from a fluid flow perspective.

The current paradigm of treatment by stents requires every cath lab to stock multiple models, each with different lengths and diameters. This can be beneficial when using a multiple stent approach to treat a lesion, potentially restoring the artery closer to the normal values presented here. The three dedicated bifurcation stent designs mentioned above come in 2 or 3 diameters and 2 or 3 lengths. In our opinion, this reduced number of offerings in device platforms is favorable as our correlation findings suggest that the current offering of stent platforms could potentially be reduced where metrics were not correlated or statistically significant. For example, the correlation results presented here suggest PV and OS area may serve as a metric for further restoring arteries to normal dimensions after bifurcation stenting. The notions of biomimicry and biomechanical homeostasis suggest this could be favorable. The current findings also suggest the offering for each dedicated bifurcation stent design may not universally fit the three left coronary artery bifurcations characterized here. In general, PV are shorter with larger areas than DV or SB, which in most cases, are similar for a given bifurcation group. Interestingly, the D1 branch of the LAD is significantly smaller than the LADdist for the group of patients 
studied here, which suggests dedicated bifurcation designs or multi-stent approaches should be further tailored to this bifurcation.

The mean values for Finet ratio(18) and $\mathrm{k}$-value(20) diameter models were closest to the literature values $(F=0.678, k=3)$ in the $\operatorname{LMCA}_{\text {bif }}(F=0.668, k=2.67)$, suggesting that either metric may be helpful to inform stent selection for this particular bifurcation. In contrast, differences from putative values for the Finet ratio and kvalue in the LAD and LCX bifurcations suggests that additional branching patterns should be established for each bifurcation region. More recent diameter models $(\underline{37}, \underline{38})$ do a better job of matching the three bifurcations studied here, with the LMCA again providing the closest match. Each bifurcation metric can be used to derive a corresponding bifurcation angle $(\underline{20}, \underline{39})$. The DV-SB angles reported here were not different between bifurcations and more closely agree with those of Murray than Finet for equivalent diameter ratios of daughter vessels. Interestingly, the present offering of dedicated bifurcation stents do not constrain bifurcation angle, but future design iterations may move in this direction to improve resulting indices of WSS( $\underline{39})$.

The current results should be interpreted within the constraints of several potential limitations. Computational representations of each artery were created up to the point where image quality degraded, so it is possible that LAD and LCX SB average areas are lower than in reality. The imaging data in this investigation was taken at a single time point in diastole approximating the period of diastasis, and images throughout the cardiac cycle (both diastole and systole) were not obtained. The movement of the coronary arteries throughout the cardiac cycle due to the pulsatility of the heart has the ability to change vessel characteristics, particularly curvature and eccentricity. Current helical cardiac CT imaging acquisition methods does not allow the ability to obtain and reconstruct coronary image data at non-diastasis portions of the cardiac cycle, an intrinsic technical limitation of this modality. Several other imaging modalities have been used to quantify geometric metrics for coronary arteries and their bifurcations. The use of the CT-based quantification techniques presented here offers a way for researchers and clinicians to rapidly identify and quantify morphometric details. The patient-specific vessel representations quantified require volumetric imaging data. This is desirable for the detailed set of metrics reported, which go beyond traditional 2D approaches or casting studies with harvested vasculature. While the use of angiography, IVUS or OCT in isolation cannot be used with the methods presented, we previously developed methods to create patient-specific coronary artery reconstructions using a combination of conventional and invasive high-resolution imaging modalities $(\underline{40})$. The conventional imaging modality can be $\mathrm{CT}$ angiography, MRI or bi-plane angiography. The high-resolution data can be OCT or IVUS. As part of this hybrid approach when using $\mathrm{CT}$ and $\mathrm{OCT}$, the $\mathrm{CT}$ segmentation parameters are iteratively adjusted to match dimensions from OCT in regions of overlap. A similar approach was used when segmenting the CT data in the current investigation, which suggests that the dimensions presented here from CT would be similar to those from OCT. While OCT data was not available for the population of patients studied, additional details and parameters for our CT segmentation process are included in the appendix. In order to get a better sense of the reliability of our methods, we also compared differences in several metrics from our results $(n=55)$ to those from another researcher in our lab on a subset of data $(n=22)$. The majority of values obtained from the subset are within $\sim 20 \%$ of values obtained from the entire population, lending weight to the reliability of the methods. The current investigation focused on normal arteries assuming that normal artery dimensions and branching patterns rooted in biomimicry (i.e. natural design) are preferential, and could therefore be the goal of interventional treatment by stenting. Nonetheless, Glagov remodeling, plaque eccentricity, or other factors may make it impossible to restore these dimensions through stenting. 


\section{Conclusion}

This work provides a foundation for elucidating common parameters from healthy coronary arteries and could be leveraged in the future for treating diseased arteries. Collectively the current results may ultimately be used for design iterations that improve outcomes following implantation of future dedicated bifurcation stents.

\section{Supplementary Material}

\section{Supp TableS1}

Segmentation Parameters for CCl-15-0588_R1

\begin{tabular}{|c|c|c|c|c|c|c|c|c|c|c|c|}
\hline $\begin{array}{l}\text { Pati } \\
\text { ent }\end{array}$ & $\begin{array}{l}\text { Initial Segmentation } \\
\text { for larger vessels }\end{array}$ & & & & $\begin{array}{c}\text { Augmented } \\
\text { segmentation for smaller } \\
\text { vessels }\end{array}$ & & & & & & \\
\hline & $\begin{array}{l}\text { Pre-processing, } \\
\text { Intensities }\end{array}$ & $\begin{array}{l}\text { Segmentati } \\
\text { on Forces }\end{array}$ & & $\begin{array}{c}\text { Numb } \\
\text { er of } \\
\text { Iterati } \\
\text { ons }\end{array}$ & $\begin{array}{c}\text { Pre-processing, Image } \\
\text { Edges }\end{array}$ & & & $\begin{array}{c}\text { Segmentati } \\
\text { on Forces }\end{array}$ & & & $\begin{array}{c}\mathrm{Nmb} \\
\text { er of } \\
\text { Iterat } \\
\text { ions }\end{array}$ \\
\hline & Intensity Thresholds & Balloon & $\begin{array}{l}\text { Curv } \\
\text { ature }\end{array}$ & & Gaussian blurring & $\begin{array}{c}\text { Edg } \\
\mathrm{e} \\
\text { cont } \\
\text { rast }\end{array}$ & $\begin{array}{l}\text { Edge } \\
\text { map } \\
\text { ping }\end{array}$ & Balloon & $\begin{array}{l}\text { Curv } \\
\text { ature }\end{array}$ & $\begin{array}{l}\text { Adve } \\
\text { ction }\end{array}$ & \\
\hline 1 & $207-1306$ & 1.0 & 0.2 & 25 & 1.0 & 0.1 & 2.0 & 1.0 & 0.2 & 1.0 & 20 \\
\hline 2 & $324-1053$ & 1.0 & 0.2 & 25 & 0.4 & 0.2 & 3.0 & 1.0 & 0.2 & 5.0 & 12 \\
\hline 3 & $256-1297$ & 1.0 & 0.2 & 20 & 1.0 & 0.1 & 2.0 & 1.0 & 0.2 & 1.0 & 15 \\
\hline 4 & $204-650$ & 1.0 & 0.2 & 20 & 1.0 & 0.1 & 2.0 & 1.0 & 0.2 & 1.0 & 20 \\
\hline 5 & $168-688$ & 1.0 & 0.3 & 15 & 1.0 & 0.1 & 2.0 & 1.0 & 0.3 & 1.0 & 15 \\
\hline 6 & $237-785$ & 1.0 & 0.2 & 10 & 1.0 & 0.1 & 2.0 & 1.0 & 0.2 & 1.5 & 20 \\
\hline 7 & $240-675$ & 1.0 & 0.2 & 20 & 1.0 & 0.1 & 2.0 & 1.0 & 0.2 & 1.5 & 20 \\
\hline 8 & $86-609$ & 1.0 & 0.2 & 25 & 1.0 & 0.1 & 2.0 & 1.0 & 0.2 & 1.5 & 20 \\
\hline 9 & $159-1197$ & 0.5 & 0.3 & 15 & 1.0 & 0.1 & 2.0 & 1.0 & 0.2 & 1.0 & 20 \\
\hline 10 & $109-711$ & 0.5 & 0.3 & 20 & 1.0 & 0.1 & 2.0 & 1.0 & 0.2 & 1.0 & 15 \\
\hline 11 & $104-865$ & 1.0 & 0.3 & 20 & 0.7 & 0.09 & 2.0 & 1.0 & 0.2 & 1.5 & 10 \\
\hline 12 & 201-805 & 2.0 & 0.2 & 15 & 1.0 & 0.1 & 2.0 & 1.0 & 0.2 & 1.0 & 15 \\
\hline 13 & $70-620$ & 1.0 & 0.2 & 20 & 1.0 & 0.1 & 2.0 & 1.0 & 0.2 & 1.5 & 25 \\
\hline 14 & $186-617$ & 1.0 & 0.2 & 20 & 1.0 & 0.1 & 2.0 & 1.0 & 0.2 & 1.0 & 20 \\
\hline 15 & $212-617$ & 1.0 & 0.2 & 20 & 1.0 & 0.1 & 2.0 & 1.0 & 0.2 & 1.0 & 15 \\
\hline 16 & $157-997$ & 1.0 & 0.2 & 20 & 1.0 & 0.1 & 2.0 & 1.0 & 0.2 & 1.5 & 20 \\
\hline 17 & $247-1029$ & 1.0 & 0.2 & 20 & 1.0 & 0.1 & 2.0 & 1.0 & 0.2 & 1.0 & 20 \\
\hline 18 & 216-535 & 1.0 & 0.2 & 25 & 0.7 & 0.15 & 2.6 & 1.0 & 0.2 & 1.0 & 20 \\
\hline 19 & $122-653$ & 1.0 & 0.4 & 25 & 1.0 & 0.1 & 2.0 & 1.0 & 0.2 & 1.0 & 15 \\
\hline 20 & $191-840$ & 1.0 & 0.2 & 20 & 1.0 & 0.1 & 2.0 & 1.0 & 0.2 & 1.0 & 20 \\
\hline 21 & $176-553$ & 1.0 & 0.2 & 20 & 0.5 & 0.14 & 2.5 & 1.0 & 0.2 & 1.5 & 20 \\
\hline 22 & $241-622$ & 1.0 & 0.2 & 20 & 1.0 & 0.1 & 2.2 & 1.0 & 0.2 & 1.0 & 10 \\
\hline 23 & $145-1250$ & 1.0 & 0.2 & 15 & 1.0 & 0.1 & 2.0 & 1.0 & 0.2 & 1.5 & 20 \\
\hline 24 & $219-666$ & 1.0 & 0.2 & 15 & 1.0 & 0.1 & 2.0 & 1.0 & 0.2 & 0.5 & 25 \\
\hline 25 & $262-1547$ & 1.0 & 0.2 & 15 & 1.0 & 0.1 & 2.0 & 1.0 & 0.2 & 1.0 & 20 \\
\hline 26 & $213-1349$ & 1.0 & 0.2 & 15 & 1.0 & 0.1 & 2.0 & 1.0 & 0.2 & 1.5 & 15 \\
\hline 27 & $124-661$ & 1.0 & 0.2 & 15 & 1.0 & 0.1 & 2.0 & 1.0 & 0.5 & 1.5 & 10 \\
\hline 28 & $179-1059$ & 1.0 & 0.2 & 20 & 0.5 & 0.1 & 2.0 & 1.0 & 0.2 & 1.5 & 15 \\
\hline 29 & $176-552$ & 1.0 & 0.6 & 20 & 1.0 & 0.1 & 2.0 & 1.0 & 0.4 & 2.0 & 15 \\
\hline 30 & $213-1432$ & 1.0 & 0.5 & 20 & 1.0 & 0.1 & 2.0 & 1.0 & 0.5 & 2.0 & 20 \\
\hline 31 & $81-497$ & 1.0 & 0.7 & 15 & 1.3 & 0.1 & 2.0 & 1.0 & 0.6 & 1.5 & 20 \\
\hline 32 & $228-626$ & 1.0 & 0.2 & 15 & 1.0 & 0.1 & 2.0 & 1.0 & 0.2 & 1.0 & 20 \\
\hline 33 & $229-621$ & 1.0 & 0.2 & 10 & 1.0 & 0.1 & 2.0 & 1.0 & 0.4 & 1.5 & 15 \\
\hline 34 & $181-784$ & 1.0 & 0.4 & 20 & 1.0 & 0.1 & 2.0 & 1.0 & 0.4 & 1.5 & 10 \\
\hline 35 & $151-645$ & 1.0 & 0.4 & 20 & 1.0 & 0.1 & 2.0 & 1.0 & 0.2 & 1.5 & 20 \\
\hline 36 & $107-378$ & 0.4 & 0.3 & 15 & 1.0 & 0.1 & 2.0 & 1.0 & 0.2 & 3.0 & 15 \\
\hline 37 & 201-530 & 1.0 & 0.4 & 20 & 1.0 & 0.1 & 2.0 & 1.0 & 0.2 & 1.5 & 20 \\
\hline 38 & $123-827$ & 1.0 & 1.0 & 20 & 1.0 & 0.1 & 2.0 & 1.0 & 0.5 & 2.0 & 15 \\
\hline
\end{tabular}




\begin{tabular}{|l|l|l|l|l|l|l|l|l|l|l|l|}
\hline 39 & $159-411$ & 1.0 & 0.5 & 15 & 1.0 & 0.1 & 2.0 & 1.0 & 0.4 & 1.5 & 15 \\
\hline 40 & $190-569$ & 1.0 & 0.5 & 20 & 1.0 & 0.1 & 2.0 & 1.0 & 0.5 & 1.5 & 20 \\
\hline 41 & $156-493$ & 1.0 & 0.5 & 20 & 1.0 & 0.1 & 2.0 & 1.0 & 0.4 & 1.5 & 20 \\
\hline 42 & $48-525$ & 1.0 & 0.5 & 10 & 1.0 & 0.1 & 2.0 & 1.0 & 0.7 & 1.5 & 10 \\
\hline 43 & $132-954$ & 0.5 & 0.4 & 15 & 1.0 & 0.1 & 2.0 & 1.0 & 0.5 & 1.0 & 20 \\
\hline 44 & $108-675$ & 1.0 & 0.4 & 20 & 1.0 & 0.1 & 2.0 & 1.0 & 0.4 & 2.0 & 15 \\
\hline 45 & $117-583$ & 1.0 & 0.4 & 15 & 1.0 & 0.1 & 2.0 & 1.0 & 0.4 & 1.5 & 20 \\
\hline 46 & $115-641$ & 1.0 & 0.5 & 10 & 0.8 & 0.1 & 2.0 & 0.5 & 0.6 & 3.0 & 20 \\
\hline 47 & $119-654$ & 1.0 & 0.5 & 15 & 1.0 & 0.1 & 2.0 & 0.5 & 0.6 & 2.0 & 15 \\
\hline 48 & $68-515$ & 0.8 & 0.8 & 20 & 1.0 & 0.1 & 2.0 & 0.8 & 0.8 & 2.0 & 20 \\
\hline 49 & $100-373$ & 1.0 & 0.8 & 15 & 1.0 & 0.1 & 2.0 & 1.0 & 0.5 & 1.5 & 15 \\
\hline 50 & $135-509$ & 1.0 & 0.5 & 15 & 1.0 & 0.1 & 2.0 & 1.0 & 0.4 & 2.0 & 20 \\
\hline 51 & $153-396$ & 1.0 & 0.5 & 20 & 1.0 & 0.1 & 2.0 & 1.0 & 0.8 & 3.0 & 20 \\
\hline 52 & $130-462$ & 1.0 & 0.2 & 20 & 1.0 & 0.1 & 2.0 & 1.0 & 0.5 & 1.5 & 20 \\
\hline 53 & $150-516$ & 1.0 & 0.4 & 20 & 1.0 & 0.1 & 2.0 & 1.0 & 0.5 & 1.5 & 10 \\
\hline 54 & $162-541$ & 1.0 & 0.5 & 15 & 1.0 & 0.1 & 2.0 & 1.0 & 0.6 & 2.0 & 15 \\
\hline 55 & $147-651$ & 1.0 & 0.2 & 20 & 1.0 & 0.1 & 2.0 & 1.0 & 0.6 & 2.0 & 20 \\
\hline
\end{tabular}

\section{Acknowledgments}

The authors gratefully acknowledge Dr. Michael Cinquegrani, Dr. Francisco Quiroz and Susan Mauermann for clinical assistance.

\section{Funding:}

This work was supported by the National Center for Advancing Translational Sciences, NIH (8UL1TR000055). Its contents are solely the responsibility of the authors and do not necessarily represent the official views of the $\mathrm{NIH}$.

Abbreviations
\begin{tabular}{|l|l|}
\hline BMS & bare-metal stent \\
\hline CT & computed tomography \\
\hline D1 & first diagonal branch of the LAD \\
\hline DES & drug-eluting stent \\
\hline LMCA & left main coronary artery \\
\hline LAD & left anterior descending artery \\
\hline LCX & left circumflex artery \\
\hline LDA & linear discriminant analysis \\
\hline OM & obtuse marginal branch of the LCX \\
\hline NH & neointimal hyperplasia \\
\hline ROI & regions of interest \\
\hline WSS & wall shear stress \\
\hline
\end{tabular}

\section{Footnotes}

Conflict of interest statement: The authors have no conflicts of interest to declare. 


\section{References}

1. Ragosta M, Dee S, Sarembock IJ, Lipson LC, Gimple LW, Powers ER. Prevalence of unfavorable angiographic characteristics for percutaneous intervention in patients with unprotected left main coronary artery disease. Catheter Cardiovasc Interv. 2006;68(3):357-362.

2. Kushner FG, Hand M, Smith SC, Jr, King SB, 3rd, Anderson JL, Antman EM, Bailey SR, Bates ER, Blankenship JC, Casey DE, Jr, et al. 2009 Focused Updates: ACC/AHA Guidelines for the Management of Patients With STElevation Myocardial Infarction (updating the 2004 Guideline and 2007 Focused Update) and ACC/AHA/SCAI Guidelines on Percutaneous Coronary Intervention (updating the 2005 Guideline and 2007 Focused Update): a report of the American College of Cardiology Foundation/American Heart Association Task Force on Practice Guidelines. Circulation. 2009;120(22):2271-2306. ]

3. Wijns W, Kolh P, Danchin N, Di Mario C, Falk V, Folliguet T, Garg S, Huber K, James S, Knuuti J, et al. Guidelines on myocardial revascularization. Eur Heart J. 2010;31(20):2501-2555.

4. Fajadet J, Chieffo A. Current management of left main coronary artery disease. European heart journal. 2012;33(1):36-50b.

5. Gundert TJ, Marsden AL, Yang W, Marks DS, LaDisa JF., Jr Identification of hemodynamically optimal coronary stent designs based on vessel caliber. IEEE Trans Biomed Eng. 2012;59(7):1992-2002. [

6. Pant S, Limbert G, Curzen NP, Bressloff NW. Multiobjective design optimisation of coronary stents. Biomaterials. 2011;32(31):7755-7773

7. Ku DN, Giddens DP, Zarins CK, Glagov S. Pulsatile flow and atherosclerosis in the human carotid bifurcation. Positive correlation between plaque location and low oscillating shear stress. Arteriosclerosis. 1985;5(3):293-302.

8. LaDisa JF, Jr, Bowers M, Harmann L, Prost R, Doppalapudi AV, Mohyuddin T, Zaidat O, Migrino RQ. Timeefficient patient-specific quantification of regional carotid artery fluid dynamics and spatial correlation with plaque burden. Med Phys. 2010;37(2):784-792.

9. Moore JE, Jr, Xu C, Glagov S, Zarins CK, Ku DN. Fluid wall shear stress measurements in a model of the human abdominal aorta: oscillatory behavior and relationship to atherosclerosis. Atherosclerosis. 1994;110(2):225-240.

10. Wahle A, Lopez JJ, Olszewski ME, Vigmostad SC, Chandran KB, Rossen JD, Sonka M. Plaque development, vessel curvature, and wall shear stress in coronary arteries assessed by $\mathrm{X}$-ray angiography and intravascular ultrasound. Medical image analysis. 2006;10(4):615-631.

11. Iwami T, Fujii T, Miura T, Otani N, lida H, Kawamura A, Yoshitake S, Kohno M, Hisamatsu Y, Iwamoto H, et al. Importance of left anterior descending coronary artery curvature in determining cross-sectional plaque distribution assessed by intravascular ultrasound. The American journal of cardiology. 1998;82(3):381384.

12. Garasic JM, Edelman ER, Squire JC, Seifert P, Williams MS, Rogers C. Stent and artery geometry determine intimal thickening independent of arterial injury. Circulation. 2000;101(7):812-818

13. Murata T, Hiro T, Fujii T, Yasumoto K, Murashige A, Kohno M, Yamada J, Miura T, Matsuzaki M. Impact of the cross-sectional geometry of the post-deployment coronary stent on in-stent neointimal hyperplasia: an intravascular ultrasound study. Circ J. 2002;66(5):489-493.

14. LaDisa JF, Jr, Olson LE, Molthen RC, Hettrick DA, Pratt PF, Hardel MD, Kersten JR, Warltier DC, Pagel PS. Alterations in wall shear stress predict sites of neointimal hyperplasia after stent implantation in rabbit iliac arteries. Am J Physiol Heart Circ Physiol. 2005;288(5):H2465-H2475.

15. Chiastra C, Migliavacca F, Martinez MA, Malve M. On the necessity of modelling fluid-structure interaction for stented coronary arteries. Journal of the mechanical behavior of biomedical materials. 2014;34:217230. 
16. Gijsen FJ, Migliavacca F, Schievano S, Socci L, Petrini L, Thury A, Wentzel JJ, van der Steen AF, Serruys PW, Dubini G. Simulation of stent deployment in a realistic human coronary artery. Biomed Eng Online. 2008;7:23.

17. Farooq V, Gogas BD, Serruys PW. Restenosis: delineating the numerous causes of drug-eluting stent restenosis. Circ Cardiovasc Interv. 2011;4(2):195-205.

18. Finet G, Gilard M, Perrenot B, Rioufol G, Motreff P, Gavit L, Prost R. Fractal geometry of arterial coronary bifurcations: a quantitative coronary angiography and intravascular ultrasound analysis. Eurolntervention. 2007;3:490-498.

19. Kawasaki T, Koga H, Serikawa T, Orita Y, Ikeda S, Mito T, Gotou Y, Shintani Y, Tanaka A, Tanaka H, et al. The bifurcation study using 64 multislice computed tomography. Catheterization and cardiovascular interventions : official journal of the Society for Cardiac Angiography \& Interventions. 2009;73(5):653-658.

20. Murray CD. The Physiological Principle of Minimum Work Applied to the Angle of Branching of Arteries. The Journal of general physiology. 1926;9(6):835-841.

21. Pflederer T, Ludwig J, Ropers D, Daniel WG, Achenbach S. Measurement of coronary artery bifurcation angles by multidetector computed tomography. Investigative radiology. 2006;41(11):793-798.

22. van der Waal EC, Mintz GS, Garcia-Garcia HM, Bui AB, Pehlivanova M, Girasis C, Serruys PW, van der Giessen WJ, Weissman NJ. Intravascular ultrasound and 3D angle measurements of coronary bifurcations. Catheterization and cardiovascular interventions : official journal of the Society for Cardiac Angiography \& Interventions. 2009;73(7):910-916.

23. Christensen KN, Harris SR, Froemming AT, Brinjikji W, Araoz P, Asirvatham SJ, Lachman N. Anatomic assessment of the bifurcation of the left main coronary artery using multidetector computed tomography. Surgical and radiologic anatomy : SRA. 2010;32(10):903-909.

24. Wolny R, Pregowski J, Witkowski A. Coronary computed tomography angiography in planning of percutaneous coronary interventions in bifurcation lesions - study design and rationale. Postepy w kardiologii interwencyjnej = Advances in interventional cardiology. 2013;9(2):155-159.

25. Yushkevich PA, Piven J, Hazlett HC, Smith RG, Ho S, Gee JC, Gerig G. User-guided 3D active contour segmentation of anatomical structures: significantly improved efficiency and reliability. Neurolmage. 2006;31(3):1116-1128.

26. Yamagishi M, Hosokawa H, Saito S, Kanemitsu S, Chino M, Koyanagi S, Urasawa K, Ito K, Yo S, Honye J, et al. Coronary disease morphology and distribution determined by quantitative angiography and intravascular ultrasound--re-evaluation in a cooperative multicenter intravascular ultrasound study (COMIUS) Circulation journal : official journal of the Japanese Circulation Society. 2002;66(8):735-740.

27. Banka VS, Baker HA, 3rd, Vemuri DN, Voci G, Maniet AR. Effectiveness of decremental diameter balloon catheters (tapered balloon) The American journal of cardiology. 1992;69(3):188-193.

28. Javier SP, Mintz GS, Popma JJ, Pichard AD, Kent KM, Satler LF, Leon MB. Intravascular ultrasound assessment of the magnitude and mechanism of coronary artery and lumen tapering. The American journal of cardiology. 1995;75(2):177-180.

29. Taylor R. Interpretation of the Correlation-Coefficient - a Basic Review. Journal of Diagnostic Medical Sonography. 1990;6(1):35-39.

30. Hinkle DE, Wiersma W, Jurs SG. Applied Statistics for Behavioral Sciences. Houghton: Mifflin; 2003.

31. Garg S, Serruys PW. Coronary stents: current status. Journal of the American College of Cardiology. 2010;56(10 Suppl):S1-S42.

32. Medical T. Side Branch Stent. 2012;2014

33. International B. Axxess Self-expanding bifurcation DES: raising the standard in bifurcation. 2013

34. Lefevre T, Chevalier B, Louvard Y. Is there a need for dedicated bifurcation devices? Eurolntervention. 2010;6(Suppl J):J123-J129. 
35. Sheiban I, Omede P, Biondi-Zoccai G, Moretti C, Sciuto F, Trevi GP. Update on dedicated bifurcation stents. J Interv Cardiol. 2009;22(2):150-155.

36. Dubois C, Adriaenssens T, Ughi G, Wiyono S, Bennett J, Coosemans M, Ferdinande B, Sinnaeve P, D'Hooge J, Desmet W. Healing responses after bifurcation stenting with the dedicated TRYTON Side-Branch Stent in combination with XIENCE-V stents: a clinical, angiography, fractional flow reserve, and optical coherence tomography study: the PYTON (Prospective evaluation of the TRYTON Side-Branch Stent with an additional XIENCE-v everolimus-eluting stent in coronary bifurcation lesions) study. Catheter Cardiovasc Interv. 2013;81(3):E155-E164.

37. Huo Y, Kassab GS. Intraspecific scaling laws of vascular trees. Journal of the Royal Society, Interface / the Royal Society. 2012;9(66):190-200.

38. Huo Y, Kassab GS. A scaling law of vascular volume. Biophysical journal. 2009;96(2):347-353.

39. Huo Y, Finet G, Lefevre T, Louvard Y, Moussa I, Kassab GS. Which diameter and angle rule provides optimal flow patterns in a coronary bifurcation? Journal of Biomechanics. 2012;45(7):1273-1279.

40. Ellwein LM, Otake H, Gundert TJ, Koo BK, Shinke T, Honda Y, Shite J, LaDisa JF., Jr Optical coherence tomography for patient-specific 3D artery reconstruction and evaluation of wall shear stress in a left circumflex coronary artery. Cardiovasc Eng Tech. 2011;2(3):212-217. 